\title{
Organization of Decorative Lighting of the Architectural Environment
}

\author{
Alla Aleksandrovna Kornilova*, Yevgeniya Mikhaylovna Khorovetskaya, Madygali Kudayberdievich \\ Tezekbayev, Bekmurat Zhumashevich Yespenbetov, Gulmira Kurmangadievna Jamankulova
}

S. Seifullin Kazakh Agro Technical University, Zhenis Avenue, 62, Nur-sultan (Astana), 010011, Republic of Kazakhstan

Received April 6, 2021; Revised August 15, 2021; Accepted August 25, 2021

\section{Cite This Paper in the following Citation Styles}

(a): [1] Alla Aleksandrovna Kornilova, Yevgeniya Mikhaylovna Khorovetskaya, Madygali Kudayberdievich Tezekbayev, Bekmurat Zhumashevich Yespenbetov, Gulmira Kurmangadievna Jamankulova, "Organization of Decorative Lighting of the Architectural Environment," Civil Engineering and Architecture, Vol. 9, No. 6, pp. 1798-1804, 2021. DOI: 10.13189/cea.2021.090613.

(b): Alla Aleksandrovna Kornilova, Yevgeniya Mikhaylovna Khorovetskaya, Madygali Kudayberdievich Tezekbayev, Bekmurat Zhumashevich Yespenbetov, Gulmira Kurmangadievna Jamankulova (2021). Organization of Decorative Lighting of the Architectural Environment. Civil Engineering and Architecture, 9(6), 1798-1804. DOI: 10.13189/cea.2021.090613.

Copyright $\bigcirc 2021$ by authors, all rights reserved. Authors agree that this article remains permanently open access under the terms of the Creative Commons Attribution License 4.0 International License

\begin{abstract}
The goal of the present research is to determine the criteria of a conceptual and theoretical model of the decorative lighting organization of the architectural environment in the regional conditions of Northern Kazakhstan. The following issues were resolved during the research: 1). the influence of historical, natural, climatic, and socio-economic factors on the decorative lighting formation of the architectural environment were determined; 2). the analysis was carried out and the features of decorative lighting of the architectural environment in the territory of the region under study were revealed (as exemplified by the city of Nur-Sultan); 3 ). the principles of forming a conceptual and theoretical model of the decorative lighting organization of the architectural environment and its elements were defined. As a consequence of conducted research, a conceptual-theoretical model of the decorative lighting organization of the architectural environment was developed based on retrospective analysis and regional features of Northern Kazakhstan. The optimality criteria of decorative lighting organization of architectural environment were also determined.
\end{abstract}

Keywords Architectural Environment, Decorative Lighting, System Standard, Regional Features, Light, Color, Model, Theory

\section{Introduction}

The theory and practice of designing the night-time image of architectural ensembles, buildings, and landscapes develop much slower than the implementation of light solutions in the advertising industry. In most cases, the possibilities of decorative lighting are not fully utilized despite their huge aesthetic potential and rapidly improving technologies. The request for innovative changes in the architectural environment arises depending on the political ambitions of state bodies or large corporations [1,2]. The success of such projects becomes a driver for both the creation and promotion of innovative solutions. However, in a broader scientific sense, not only the design of artificial light systems but also the optimization of daylight usage falls into the sphere of decorative lighting. The need for the new methods of architectural shaping is dictated by the need to introduce in the building of resource-saving lighting technologies, ecological infrastructure including alternative energy sources [3].

With changes in historical and socio-economic conditions, the need to develop new criteria and approaches in the decorative lighting organization of the architectural environment that would best suit the living conditions of people increases. Light and color have acquired a new value in architecture, which became a tool for forming a panorama of the architectural environment, 
its lighting, and displaying details [4].

The search for an optimal balance of natural and artificial lighting of the architectural environment contributes to the formation of a high-quality, safe, and psychologically comfortable decorative lighting of the architectural environment and environment at home, at work, in places of recreation and entertainment.

We believe that existing publications on the decorative lighting of the architectural environment, in this case, can be divided into three main directions.

The first direction is associated with theoretical and historical aspects of the decorative lighting of the architectural environment. The analysis of these works helped us in the interpretation of archival and historical documents.

Thus, the works of N.A. Nosov [5], E.M. Khorovetskaya [6], Efimov [7], A.A. Kornilova [8] A.I. Turekpaeva [9], N.I. Shchepetkov [10] consider the theoretical aspects of decorative lighting in the architectural environment.

The historical and modern experience of urban light and architectural lighting is considered by N.I. Shchepetkov. A.V. Efimov who notes that each type of light pool consists of regional components of the natural landscape and determines the nature of the light-color palette and its dynamics.

The second direction is associated with decorative lighting of the architectural environment;

The decorative lighting of the architectural environment is presented in the works of Yu.B. Aizenberg [11], V.R. Stevens [12], D. Schreuder [13], which, along with general questions, consider possible options for decorative lighting in individual elements of the architectural environment.

The third direction is associated with socio-psychological aspects of the perception of the decorative lighting of the architectural environment.

Socio-psychological aspects of the perception of light and color are one of the main factors in the decorative lighting of the architectural environment, which is noted in the works of M.K. Tezekbaev, [14], E.V. Logunova [15], P. Rode [16]. Thus, M.K. Tezekbaev notes that visual perception is associated with the psychological mood of the residents of the city. Kornilova et al. study the principles of the decorative lighting of the architectural environment as a factor of increasing the comfort of living [17].

Thus, despite a significant number of studies, we believe that they do not disclose issues on the integrated use of light and color in the architectural environment, as well as issues of the decorative lighting of the architectural environment as a factor in improving the comfort of living.

At the present stage, both in theory and in practice, there is no scientifically-based unified system of decorative lighting of the architectural environment, equated to the general scheme of the decorative lighting of the entire city, which would serve as a reference point for solving the issues of decorative lighting of individual districts, buildings, and constituent elements. Therewith, it is necessary to take into account not only the economic component but also functional-practical, aesthetic, socio-cultural, and emotional-psychological aspects.

In this regard, today it is necessary to foresee new scientific, theoretical, and practical approaches to the light-decorative organization of the architectural environment as a whole (the architectural environment and its components, exteriors, and interiors).

The scientific novelty, the theoretical and practical significance of this work lies in the following:

- for the first time in Northern Kazakhstan, the decorative lighting of the architectural environment is considered as the interaction of a complex of environment-forming factors, methods, and techniques for the formation of comfortable decorative lighting in an urban environment;

- the factors for the formation of comfortable decorative lighting of the architectural environment have been identified;

- the principles of decorative lighting zoning of the territory of the settlement have been developed;

- the principles of the formation of the decorative lighting of the architectural environment have been determined.

- the stages of forming comfortable decorative lighting of the architectural environment have been determined.

The research aims to develop a predictive conceptual and theoretical model of the light-decorative organization of the architectural environment and its components.

\section{Materials and Methods}

\subsection{Study Design}

Based on the research goal, we chose a mixed type of research design, namely a combination of data collection and analysis requirements. In particular, we considered the features of combinatorics of elements of the qualitative and quantitative approaches within the framework of one study. In the work, the following methods were used: analysis of documents (archival and historical materials), the architectural design method, the expert survey and the survey of the population. All analytical conclusions were based on field research from 2005 to 2020. Sociological methods were used in surveys of the population and experts.

The following stages of our research were highlighted:

1st stage $-2005-2010$

At the first stage of the population survey, 1,230 people were interviewed. The survey was conducted in 30 localities of Northern Kazakhstan, different in administrative significance and population size, as well as located in different natural, economic, historical, national, 
and demographic conditions. In the course of the expert survey, 275 people were interviewed at the first stage.

2nd stage - 2011-2015

At the second stage of the population survey, 1,340 people were interviewed. The survey was conducted in the same 30 localities to compare the results of the study with the first stage. In the course of the expert survey, 292 people were interviewed at the second stage.

3rd stage $-2016-2020$

At the third stage of the population survey, 1,520 people were interviewed. The survey was conducted in the same 30 localities to compare the results of the study with the first stage. In the course of the expert survey, 315 people were interviewed at the third stage.

\subsection{Research Instruments and Procedures}

\subsubsection{Document Analysis}

In the process of document analysis, we examined archival and historical documents in the cities of Northern Kazakhstan (Nur-Sultan, Petropavlovsk, Pavlodar, Kostanay, Kokshetau) for 2005-2020.

\subsubsection{Architectural Design Methods}

Architectural design methods were used to form an decorative lighting of the architectural environment, following the wishes of the population and economic expediency based on the results of technological scouting.

\subsubsection{Survey of the Population}

Questionnaires to survey the population were developed to clarify the socio-economic factors for the decorative lighting of the architectural environment, as well as to identify the emotional and psychological aspects of the perception of the decorative lighting of the architectural environment of various age and social groups of the population.

More than 120 nationalities live in the territory of Northern Kazakhstan. Therewith, most of the residents are of Kazakh and Russian nationality. The share of Kazakhs in the region is $54.42 \%$, Russians $-32.03 \%$. In this regard, the questionnaires were compiled in Kazakh and Russian.

The face-to-face method of questioning was used in the process of interviewing the population:

- when filling out questionnaires during an individual conversation;

- when filling out questionnaires during a group conversation.

At all stages of the work, one way of organizing the sample was determined - according to a typical selection. The sample size was determined by the formula [18]:

$$
n=\frac{t^{2} G^{2} N}{N \Delta^{2}+t^{2} G^{2}}
$$

Where $\mathrm{n}$ is the sample size

$\mathrm{N}$ - the number of units of the general population;

$t$ is the ratio of the confidence error to the average error, the so-called normalized deviation. Each value of $t$ corresponds to a certain probability that the sampling error does not exceed the confidence error $\Delta^{1}$;

$\mathrm{G}$ - the mean square deviation of the general population;

$\Delta$ - acceptable error;

$\mathrm{G}$ - was determined based on previous studies.

\subsubsection{Expert Survey}

One of the constituent aspects of achieving the research goal, accordingly, the forecast of the development of the decorative lighting of the architectural environment, was determined based on the expert survey method. The purpose of this expert survey was to obtain a competent opinion from experts on the formation of comfortable decorative lighting of the architectural environment. In the course of the work, the experts were offered a questionnaire of 13 questions covering the main conditions for creating comfortable decorative lighting of the architectural environment. The experts were specialists working in the field of architecture, urban planning, and design, specialists in civil engineering, cultural workers, and teachers.

\section{Results}

\subsection{Document Analysis Results}

During the research, it has been revealed that the level and features of the color perception culture of the population, as well as cultural and historical traditions in the formation of architecture in Kazakhstan, determine the criteria of the comfortable decorative lighting of the architectural environment. Thus, one of the most striking examples of creating decorative lighting composition in North Kazakhstan is the ensemble of the main square in the new capital of Kazakhstan, the city of Nur-Sultan. The main artistic idea of the project was the image of a representative decorative lighting ensemble with Baiterek - the dominant decorative lighting of the panorama of the square.

\subsection{Architectural Design}

According to the results of the study, the following was revealed:

- lack of master plans for the formation of the decorative organization of the architectural environment in the cities of Northern Kazakhstan;

- the decorative lighting of the architectural environment in cities is solved fragmentarily;

- we identified the color characteristics of construction and finishing materials which serve as the basis for 
constructing a colored light layout of space. The aesthetic expressiveness and acceptable contrast of a colored light environment are based on two types of relations between its structural elements contrast-based contraposition and nuanced consistency. An important quality of light and color is their shape-generating properties. To solve the set problem of the decorative lighting organization of architectural space, a system standard of the colored light environment was defined.

\subsection{Population Survey Results}

It was found during the survey of the population that the visual perception of the decorative lighting of the architectural environment is formed under the influence of the general reaction of respondents:

Firstly, the decorative lighting of the architectural environment is as a design solution.

Secondly, the idea of the decorative lighting of the architectural environment is individual for each respondent and differs significantly from the view of specialists.

Thirdly, the decorative lighting of the architectural environment in the interior of each respondent is considered a functional necessity.

Most of the respondents (78\%) note that the decorative lighting of the architectural environment brings great expressiveness and individuality to urban architecture.

When processing the questionnaire data, four groups were identified from the respondents based on "aesthetic potential" (aesthetic needs); that is, the attitude and requirements of city residents to the decorative lighting of the architectural environment.

Taking into account the results of a sociological study on social groups of the population, the criteria for the attitude and use of light in the architectural environment have been identified, which significantly affect the definition of the basic principles of the decorative lighting of the architectural environment.

\subsection{Expert Survey Results}

The survey of experts allowed establishing that the attitude to the decorative lighting of a comfortable architectural environment largely depends on the competence of the expert, as well as identifying the main components of the perception of the decorative lighting of the architectural environment and their use in the design of the city, which in turn will contribute to a comfortable, harmonious architectural environment both during the day and at night. Therewith, the factors determining the expediency of the decorative lighting of the architectural environment were identified, which are grouped into blocks of ergonomic and hygienic requirements for this environment, the most important of which are:
- $\quad$ taking into account the nature of the activities of people for whom this decorative lighting is intended;

- the time and nature of people's stay in the light-emitting environment; taking into account the age of the population arriving in this environment;

- the required decorative lighting mode.

The nature of a particular environment sets its own requirements. The analysis of the results of the survey of experts allowed identifying the principles in the formation of comfortable decorative lighting and identifying the stages. The main principles are:

1) The principle of spatial decorative lighting zoning of the entire locality ( $86 \%$ of the experts surveyed suggest the allocation of this principle).

2) The principle of decorative lighting autonomy, determined by the laws of color balance and harmony of color combinations ( $79 \%$ of the experts surveyed).

3) The principle of natural decorative lighting context in the formation of the architectural environment and objects of urban space ( $73 \%$ of the experts surveyed).

4) The principle of development of achievements of decorative lighting historical heritage ( $51 \%$ of the surveyed experts suggested highlighting this principle).

When describing the expressiveness of decorative lighting of city, three successive stages of decorative lighting in a comfortable architectural environment are identified. In the first stage, the aesthetic significance of structural elements is determined in the system space. In the second stage, territory is allocated by the nature of the architectural and planning solutions of the city public centers. In the third stage, the volumetric and spatial composition of individual complexes is considered. With the growth of cities, their compositional structure changes, which dictates the need to create a more flexible system of the decorative lighting of the architectural environment. At that, we propose a solution to the two main tasks. The first is creating the decorative lighting of the architectural environment that is capable of development. The second is ensuring success in the development of the decorative lighting of the architectural environment. The laws of scale, tectonics, rhythm and meter of daytime architecture provide the basis for creating decorative lighting of the architectural environment.

It should be noted that $72 \%$ of the experts surveyed noted that it is necessary to adhere to the differentiation of the use of light when forming decorative lighting architectural environment, noting that there should be a minimum amount of light on residential buildings in dormitory districts of the city, therewith, focusing on individual elements of a residential building (entrances, stairwells, built-in and attached rooms) - in the decorative lighting of gardens, parks, squares, alleys, playgrounds, pedestrian paths. 


\section{Discussion}

The analysis and generalization of the collected material in the course of the research allowed developing a conceptual and theoretical model of the decorative lighting of the architectural environment and its components.

The conceptual and theoretical model is based on the following principles of decorative lighting organization of the architectural environment:

1. Accounting for regional, cultural, historical, natural, climatic, national, psychological, socio-economic, scientific, and technical factors and features.

2. Implementing a flexible approach to the decorative lighting organization of the architectural environment, allowing for further development and change.

3. Carrying out decorative lighting of each structural element taking into account the architectural means of space organization.

We defined the principles of forming the general scheme of the decorative lighting organization of the architectural environment and the stages of its construction.

The implementation of the general scheme is planned in stages.

The first stage involves the study of regional conditions. As a result, data on nature and climate, natural color dynamics are provided (in the form of a description of tables and sketches), the opinion of residents and experts, as well as the existing functional zoning of the city, are taken into account. The result of the first stage is the development of a scheme of decorative lighting zoning of the city as a whole. In the decorative lighting zoning of the city, zones are allocated depending on their functional significance, the planned decorative lighting saturation, and the opinion of social groups of residents of the city.

At the second stage, it is planned to search for the optimal decorative lighting solution within the entire city, taking into account the decorative lighting zoning of the city territory. Pre-project and project analysis at this stage is accompanied by a review of the existing state of the decorative lighting of the architectural environment of the locality with the fixation of the reference light carriers.

The third stage provides for the decorative lighting within separate decorative lighting zones on the territory of the residential area of the microdistrict and its elements. At this stage, a multi-level system of decorative lighting of the architectural environment is envisaged - the zonal level, the district-microdistrict level, and the node level.

The fourth stage is the decorative lighting solution to structural elements for each light-color zone of the city. The main goal of the work at this stage is the decorative lighting solution of individual elements and their details, based on the results of the previous stages.

The task of the conceptual and theoretical model of the decorative lighting of the architectural environment is to develop a model for the formation of the optimal variant of the decorative lighting solution to the urban space as a whole and its elements, which is achieved by:

- creation of a functionally complete environment for social life.

- creation of an aesthetically meaningful environment.

When developing the general scheme of the decorative lighting of the city, the following factors are taken into account: natural and climatic, psychological, historical and cultural, national, resource, architectural and artistic, scientific, and technical.

Taking into account the above factors will allow:

- natural and climatic - ensuring the comfort of stay of the population in the architectural environment of a particular locality at any time of the year and at any time of the day:

- $\quad$ historical and cultural - provides for a light-color solution of the architectural environment, taking into account national and historical characteristics:

- resource - the decorative lighting solution of the architectural environment should be brought into full compliance with the resource factors.

It is proposed to use a monitoring and evaluation system when determining the perspective concept of the development of the decorative lighting of the architectural environment. Therewith, it is proposed to lay the basis for the comfort of living, which includes the conditions for the population to stay in the architectural environment in the evening and at night. To characterize the comfort of living of the population, several socio-economic indicators are used and formed based on materials collected in the course of a sociological survey and in the process of studying this problem. The main indicators that characterize the living conditions of the population in a particular locality include:

1. emotional-psychological and physiological effects of light and color on a person;

2. state of the environment;

3. socio-psychological models of life of the population;

4. the relationship of the diversity of the constituent elements.

At the same time, it should be emphasized that all these indicators acquire a certain meaning only in combination with light and color. At the present stage, the formation of an architectural environment without taking into account light and color in both the interior and exterior is unthinkable.

Scientific foresight and a comprehensive forecast are no less important components in the development of the general scheme of the decorative lighting of the city and further - schemes of decorative lighting zoning.

The use of scientific foresight in the field of decorative lighting of the architectural environment in the Republic of Kazakhstan is at an early stage. Forecasts allow shaping the future and preventing undesirable developments. In this case, the prognostic is based on the assessment of natural, national, historical, and social phenomena. In the course of the research, existing information was processed into 
information about future development.

An important feature of the integrated forecast in the formation of the decorative lighting of the architectural environment is the dynamics of the architectural and planning structure of settlements, urban objects, and their elements considered in the forecast.

When developing the general scheme of the decorative lighting of the city and the schemes of decorative lighting zoning, the main modern trends in the development of urban planning and the decorative lighting of the architectural environment were taken into account, which can be formulated as follows:

- trends in the design of the architectural environment as a whole and its individual elements;

- lifestyle-related trends;

- trends in the development of lighting technology;

- trends related to the decorative lighting of the architectural environment.

In this case, it is proposed to consider the decorative lighting of the architectural environment as a socio-urban aspect, including social design, taking into account the results of a sociological study, as well as round-the-clock, year-round comfort of staying in the architectural environment. We obtain the optimal variant of the decorative lighting of the architectural environment in the synthesis of social, aesthetic and urban factors.

\section{Conclusions}

The main tasks of the decorative lighting of the architectural environment were studied in the course of the work, based on field studies, a sociological survey, and the study of modern literary sources on the issues of the decorative lighting of the architectural environment at the international level. Having identified several unresolved issues, several solutions to the problems were proposed. Therewith, attention was focused on the formation of decorative lighting in a comfortable architectural environment.

General scheme of the decorative lighting of the architectural environment at various levels of urban space was developed. The stages of the formation of the decorative lighting in the architectural environment were defined. The principles of decorative lighting zoning of the territory of the settlement, as well as the principles of forming a comfortable architectural environment, were revealed.

The implementation of the developed concepts in practice is facilitated by the proposed principles, which define the sequence of work.

Continuation of work in this direction will allow studying in detail the relationship "man-light-space" and identifying more perfect directions in the formation of the architectural environment, which includes the exterior and interior.
Prospects for the development of scientific and practical research on the development of a general scheme for the lighting and decorative organization of the architectural environment, as well as on the decorative lighting zoning of urban areas and the developed principles will be aimed at testing them by introducing them into production during the construction, reconstruction and renovation of both urban and rural settlements.

The proposed method can be used in design and construction organizations when solving issues on the decorative lighting of the architectural environment. It can be used in educational institutions for training specialists in the field of architecture, urban planning, and design, and it can also be used in administrative, public, and private structures responsible for the development and improvement of cities and rural settlements.

The achievement of comfortable decorative lighting in an architectural environment in the future will be determined by a set of measures aimed at introducing high-quality conceptual projects of the decorative lighting of the architectural environment into production.

\section{REFERENCES}

[1] N. A. Nazarbayev. Strategy "Kazakhstan-2050" a new political course of the established state, Nur-Sultan, 2012.

[2] N. A. Nazarbayev. Strategic development plan of the Republic of Kazakhstan until 2025, Nur-Sultan, 2018.

[3] V. G. Chudinova, O. R. Bokov. Possibilities of Architectural Lighting to Create New Style, IOP Conf. Ser.: Mater. Sci. Eng., Vol.262, 012147, 2017.

https://iopscience.iop.org/article/10.1088/1757-899X/262/ $1 / 012147$

[4] D. Dbowska. Light in architecture as an inspired theme, IOP Conference Series: Materials Science and Engineering, Vol.245, No.4, 042038, 2017.

[5] N. A. Nosov. Virtualnaya psikhologiya [Virtual psychology], Agraf, Moscow, 2000.

[6] E. M. Khorovetskaya. Svet i tsvet v arkhitekture [Light and color in architecture], Seifullin Readings - 12: Youth in science - innovative potential of the future, Vol.1, No.3, 239-240, 2016.

https://kazatu.edu.kz/assets/i/science/sf12_arh_110.pdf

[7] A. V. Efimov. Dizain arkhitekturnoi sredy [Design of Architectural Environment], Moscow, 2019.

[8] A. A. Kornilova, S. M. Tyurin. Istoricheskie aspekty i vzaimodeistviya arkhitektury i reklamy [Historical aspects and interactions between architecture and advertising], Vestnik "KazGASA", Vol.1, No.51, 34-41, 2014.

[9] A. I. Turekulova, G. R. Iskhojanova. New formats of social design of urban spaces, Problems of Arts and Culture", Azerbaijan national academy of sciences institute of Architecture and art, Vol.4, No.70, 6-14, 2019. 
[10] N. I. Shchepetkov. The light Image of High-Rise Buildings, Light and Engineering, Vol.23, No.1, 32-39, 2015.

[11] Yu. B. Aizenberg, P. V. Plyaskina, M. A. Faermarka. Spravochnaya kniga po svetotekhnike [Lighting Engineering Reference Book], Publishing House Znak, Moscow, 2006.

[12] W. R. Stevens. Building physics: lighting: seeing in the artificial environment, 3rd ed., Pergamon press, Oxford, 2013.

[13] D. Schreuder. Outdoor lighting: physics, vision, and perception, Springer Science and Business Media, Amsterdam, 2008.

[14] M. K. Tezekbaev, E. M. Khorovetskaya. Svetotsvetovoe formirovanie arkhitekturnoi sredy kak faktor povysheniya komfortnosti prozhivaniya [Light-color formation of the architectural environment as a factor in increasing the comfort of living], Evraziiskoe Nauchnoe Obedinenie, Vol.12, No.58, 294-297, 2019.
[15] E. V. Logunova, Yu. E. Shelepin, N. A. Shabalina, A. A. Britikov, S. V. Pronin. Izuchenie ekologicheskoi bezopasnosti vizualnoi sredy [Study of the ecological safety of the visual environment], Biotekhnosfera [Biotechnosphere], Vol. 1-2, 36-41, 2014.

[16] P. Rode, R. Burdett, G. Robazza, J. Schofield. Cities, and energy. Urban morphology and heat energy demand, The London School of Economics and Political Science, London, 19-25, 2014.

[17] A. A. Kornilova, Y. M. Khorovetskaya, S. E. Mamedov, T. Z. Ospanov, D.Y. Sarsembayeva. Territory management: Urban planning and recreational planning of populated areas in the Republic of Kazakhstan in the second half of the $20^{\text {th }}$ century, Journal of Environmental Management and Tourism, Vol.10, No.6, 1295-1302, 2019.

[18] M. D. Spector. Metodologiya i metodika nauchnykh issledovanii [Methodology of scientific research], Astana, 2009. 